\title{
Leachate Treatment Using Constructed Wetlands Technique
}

\author{
M. G. Prathap ${ }^{1 *}$, Mr. D. Justus Reymond ${ }^{2}$, Mr. J. S. Sudarsan ${ }^{3}$, \\ Dr. V. T. Deeptha ${ }^{4}$ \\ ${ }^{I}$ Student, M.Tech Environmental Engineering, Srm University, Kancheepuram District \\ ${ }^{2,3,4}$ Assistant Professors,Dept Of Civil Engineering, Srm University, Kancheepuram District
}

\begin{abstract}
Constructed wetland treatment was an engineered method of purifying waste water by letting it through soil filters on which natural wetland species are grown. It was considered as an effective and reliable treatment and has found wide usage. The main study of this research is to study the best effective method for treating Leachate using constructed wetlands technique. The pollutants were removed by various physical, chemical and biogeochemical processes like sedimentation, absorption, nitrification and phytoremediation. The aim of this research was to study the effectiveness of the wetland plant Typha in the treatment of Leachate wastewater. A model wetland unit of length, width and depth of $60 \mathrm{~cm}, 40 \mathrm{~cm}$ and $30 \mathrm{~cm}$, respectively was built with slight slope of $1 \%$ between inlet and outlet zones. Typha Species were transplanted into the model unit and subjected to industrial wastewater. As the leachate has more toxic materials in it, we can't use the leachate directly into the wetlands. In this study, Leachate and domestic sewage water was mixed in 1:2 ratios and then used in the constructed wetland. Reduction in BOD and COD values was about $70-75 \%$ and $75 \%$ respectively in five days and completely below the discharge limits.
\end{abstract}

Key words: Constructed wetland, TyphaLatifolia, Leachate

\section{Introduction}

Constructed wetlands have been used widely for the treatment of municipal, industrial and agricultural wastewater, as well as for urban storm water. This is owing to their high nutrient absorption capacity, simplicity, low construction, operation and maintenance costs, low energy demand, process stability, low excess sludge production and potential for creating biodiversity. Properly designed and constructed man-made wetland ecosystems are extremely efficient at utilizing and cleaning nutrient-rich waters. Moreover, it has gained increasing acceptance for many types of bioremediation, including mining and agribusiness wastewater. In general, there are two basic types of constructed wetlands, the free water surface (FWS) wetland and the subsurface flow (SF) wetland. Both types utilize emergent aquatic vegetation and are similar in appearance to a marsh. The FWS wetland typically consists of a basin or channels with some type of barrier to prevent seepage, soil to support the roots of the emergent vegetation, and water at a relatively shallow depth flowing through the system. The water surface is exposed to the atmosphere, and the intended flow path through the system is horizontal.The SF wetland consists of a basin with a barrier to prevent seepage, but the bed contains a suitable depth of porous media. Rock or gravel is the most commonly used media types. The media support the root structure of the emergent vegetation. The design of these systems assumes that the water level in the bed will remain below the top of the rock or gravel media. The FWS systems have the advantage of requiring less land area for wastewater treatment. Moreover, they have the ability to filter, absorb and retain particulate matters, nutrients or other pollutants in wastewater. Constructed wetlands are generally built on uplands and outside floodplains or floodways in order to avoid damage to natural wetlands and other aquatic resources. Wetlands are frequently constructed by excavating, backfilling, grading, diking and installing water control structures to establish desired hydraulic flow patterns. If the site has highly permeable soils, an impervious, compacted clay liner is usually installed and the original soil placed over the liner. Wetland vegetation is then planted or allowed to establish naturally.

\section{Study Area}

\section{Materials And Methods}

The waste water for my project work was taken from Perungudi Dumping Yard which is located $10 \mathrm{kms}$ from the centre of Chennai City and also $1.2 \mathrm{kms}$ from Perungudi village. This dumping yard lies between $2 \mathrm{~km}$ to $3 \mathrm{~km}$ west of Buckingham Canal and $3.5 \mathrm{~km}$ to $4.5 \mathrm{~km}$ west of Bay of Bengal Coastline. This dumping yard is located in Old Mahablipuram Road (Now named as IT Express way). This dumping yard falls under Zone II of the Seismic Zoning as per IS 1893-1975. This site is located in central northern part of a large topographic depression called as Pallikkaranai 
depression. The height of marshland around the base of the present waste dump range between MSL and $+1 \mathrm{~m}$ above MSL.

\section{Sample Collection Points}

Wastewater sampling was performed by one of the two methods, grab sampling and composite sampling. Composite sampling was the type of sampling that has been used in the collection of wastewater. Composite sampling consists of a collection of numerous individual discrete samples taken at regular intervals over a period of time, usually $24 \mathrm{hrs}$. The wastewater samples were taken using a gouge from a depth of $10 \mathrm{~cm}$. The samples were stored in polyethylene plastic bottles, transported to the laboratory on the same day and stored in the dark at $4^{\circ} \mathrm{C}$ until making the experimental procedure.

\section{Methodolgy}

The local wetland species was collected from nearby area and grown prior to transplantation in the pilot unit.The wetland unit was designed and constructed as a lab scale prototype model as per USEPA guidelines. The plants was transplanted into the wetland unit and was allowed to grow for one month. The wastewater was tested for basic parameters so that the levels of pre-treatment required was established.Once the plants was established in the unit, wastewater was poured into the wetland unit. The parameters ( $\mathrm{pH}, \mathrm{BOD}, \mathrm{COD})$ at both the inlet and outlet was tested each time. Analysis of data - efficiency of treatment was calculated as percentage difference between inlet and outlet. Statistical analysis was conducted on the data.

\section{Statistical Analysis}

\section{Result}

From the Statistical Analysis, the following results could be inferred

i. $\quad \mathrm{pH}$ values were found to significant among the trials and setup individually but in combination of trials and setup it was found to insignificant

ii. BOD values were found to significant among the trials and setup individually 1abut in combination of trials and setup it was found to insignificant.

iii. COD values were found to be significant in trials but in setup and combination of trials $\&$ setup it was found to be insignificant.

Also from this statistical analysis, Integrated Constructed Wetlands were found to be effective method for treating Leachate with TyphaLatifolia as Vegetation

\section{Conclusion}

In this project, the Lab Scale Model for Wetlands Setup using TVA method was designed. The project was made as per the methodology. The characteristics of leachate taken from dumping yard were studied by testing each parameter in the Lab. As the plants cannot handle the toxic waste directly, the Leachate was diluted with domestic wastewater in 1:2 ratios and applied in the wetland unit. The diluted Leachate was poured into the three setups namely Horizontal, Vertical and Integrated Wetlands.

The parameters (such as $\mathrm{pH}, \mathrm{BOD}, \mathrm{COD}$, Turbidity, Conductivity, TDS and Hardness) were studied for each trial for 24, 48, 72, 96 and 120 hours which was collected from the outlet after pouring the leachate into the wetlands. Four trials were carried on for a period of one month. The BOD and COD were found to be reduced by $70-75 \%$ and $72-76 \%$ respectively. From these trials, the Integrated Constructed Wetlands was found to be very effective in treating Leachate with TyphaLatifolia as its vegetation. 


\subsection{Scope For Future Study}

In future this can be extended for testing other type of vegetation and this lab scale model could be expanded to field setup for treating Leachate. With help of adsorbents, the Leachate can be efficiently treated.

\section{References}

[1]. Ahmad Md Noor, Lim Chin Shiam, Fong Wai Hong, SuryaniSoetardjo and Abdul Khalil.H.P.S, “ Application of Vegetated Constructed Wetland with Different Filter Media for Removal of Ammoniacal Nitrogen and Total Phosphorus in Landfill Leachate" April 2012, Volume 3, No.2 International Journal of Chemical and Environmental Engineering

[2]. Ain NihlaKamarudzaman, Nor Shazwani Ismail, Roslaili Abdul Aziz and MohdFaizalAbJalil, "Removal of Nutrients from Landfill Leachate Using Subsurface Flow Constructed Wetland Planted With Limnocharisflavaand Scirpusatrovirens", October 2010 International Journal of Chemical Engineering and Applications, Vol. 1, No. 3, ISSN: 2010-0221

[3]. Ain NihlaKamarudzaman, Roslaili Abdul Aziz, and MohdFaizalAbJalil, "Removal of Heavy Metals from Landfill Leachate Using Horizontal and Vertical Subsurface Flow Constructed Wetland Planted with Limnocharisflava", International Journal of Civil \& Environmental Engineering IJCEE-IJENS Vol:11 No:05

[4]. Ain NihlaKamarudzaman, Roslaili Abdul Aziz, and MohdFaizalAbJalil, "Removal of Iron (Fe) from Landfill Leachate Using Horizontal and Vertical Subsurface Flow Constructed Wetland System Planted With LimnocharisFlava”, APRIL 2012,International Journal of Civil \& Environmental Engineering.

[5]. AndrzejBialowiec, Laura Davies, Antonio Albuquerque, Peter F. Randerson, "Nitrogen removal from landfill leachate in constructed wetlands with reed and willow: Redox potential in the root zone". Journal of Environmental Management 97 (2012) 22 27

[6]. Ewa Wojciechowska, Magdalena Gajewska, Hanna Obarska-Pempkowiak, "Treatment of Landfill Leachate by Constructed Wetlands Three Case Studies"Polish J. of Environ. Stud. Vol. 19, No. 3 (2010), 643-650

[7]. Lavrova.S, Koumanova.B., "LANDFILL LEACHATE PURIFICATION IN A VERTICAL FLOW CONSTRUCTED WETLAND WITH/WITHOUT PRELIMINARY AEROBIC TREATMENT”' Journal of the University of Chemical Technology and Metallurgy, 46, 3, 2011, 299-304

[8]. PetrosGrafias, Nikolaos P. Xekoukoulotakis, DionissiosMantzavinos,EvanDiamadopoulos, "Pilot treatment of olive pomace leachate by vertical-flow constructed wetland and electrochemical oxidation: An efficient hybrid process" water research 44 ( 2010 ) $2773-2780$

[9]. SitiHaryaniChek Rani, Mohd. Fadhil Md. Din, Mohd. BadruddinMohdYusof and ShreeshivadasanChelliapan, "Overview of Subsurface Constructed Wetlands Application in Tropical Climates", Universal Journal of Environmental Research and Technology 2011, Volume1, Issue 2: 103-114. 